\title{
Exercise and spirulina control non-alcoholic hepatic steatosis and lipid profile in diabetic Wistar rats
}

Leandro P Moura*, Guilherme M Puga, Wladimir R Beck, Inaian P Teixeira, Ana Carolina Ghezzi, Gláucio A Silva and Maria Alice R Mello

\begin{abstract}
Background: Diabetes mellitus is associated with metabolic dysfunctions, including alterations in circulating lipid levels and fat tissue accumulation, which causes, among other pathologies, non-alcoholic fatty liver disease (NAFLD).

Aim of the study: The objective of this study was to analyse the effects of physical exercise and spirulina intake on the control of NAFLD in diabetic Wistar rats.

Methods: Diabetes was induced in the animals through intravenous administration of alloxan. The rats were divided into four groups: Diabetic Control (DC) - diabetic rats fed with a control diet and no physical exercise; Diabetic Spirulina (DS) - diabetic rats fed with a diet that included spirulina; Diabetic Spirulina and Exercise (DSE) diabetic rats fed with a diet that included Spirulina and that exercised; and Diabetic Exercise (DE) - diabetic rats fed with a control diet and that exercised.

Results: The groups DS, DSE, and DE presented lower plasma concentrations of LDL cholesterol than DC, as well as lower levels of total liver lipids in groups DS, DSE, and DE in comparison to DC.

Conclusion: Thus, spirulina appears to be effective in reducing total circulating levels of LDL-cholesterol and hepatic lipids, alone or in conjunction with physical exercise in diabetic rats.
\end{abstract}

\section{Introduction}

Type 1 diabetes (DM-1), is an autoimmune illness that primarily affects young people. Because patients with type 1 diabetes do not produce sufficient quantities of insulin, they are dependent on exogenous insulin to maintain blood glucose at normal levels. In turn, type 2 diabetes (DM-2) occurs more slowly and later in life (after forty years of age) than type 1.

The complications associated with diabetes are severe. The illness is one of the main causes of blindness, kidney disease, macrovascular disease and atherosclerosis, liver disease and a variety of debilitating neuropathies that diminish the quality of life and life expectancy of the patients [1]. The imbalance of the circulating lipid

\footnotetext{
* Correspondence: leandropereiram@hotmail.com

São Paulo State University "Júlio de Mesquita Filho". Department of Physical Education. Institute of Biosciences. Laboratory of nutrition, metabolism and exercise. Av 24A, 1.515, Bela Vista - 13.506-900 - Rio Claro, SP, Brazil
}

profile is a consequence of diabetes mellitus [2]. According to Carew et al. [3], the imbalance in the concentration of serum lipoproteins can promote the movement of cholesterol from peripheral tissues to the liver for catabolic excretion. In cases where this transference to the liver is high and the catabolic level is low, fat can accumulate in this organ, causing non-alcoholic fatty liver disease (NAFLD). Furthermore, chronically high concentrations of serum lipids associated with a low level of catabolism can create the same condition. This illness is characterised by the presence of large depots of fat in the liver and the absence of inflammatory processes and is known as hepatic steatosis [4].

In addition to dietary control, physical exercise has been heavily used as a non-pharmaceutical treatment for the control and reduction in abnormal levels of circulating lipids and glucose in individuals with metabolic dysfunctions such as diabetes $[5,6]$.
C Biomed Central 
From this perspective, functional foods have been used for the control of these metabolic dysfunctions. Some authors have demonstrated that spirulina intake can regulate cholesterol, increase the antioxidant capacity, and improve insulin resistance and the uptake of glucose [7-9].

Spirulina is a helical blue-green alga, which contains 65 to $70 \%$ protein $[10,11]$. Although it has a slightly reduced digestibility [12], it appears to be a good food source of protein. In addition, some studies show that spirulina has beneficial effects on the treatment of malnutrition $[13,14]$ and on other pathologies such as obesity $[13,15]$, hypercholesterolaemia $[13,11]$, arterial hypertension [13,16,17] and diabetes mellitus [13].

In agreement with Hosoyamada et al. [9], the watersoluble fraction of spirulina is effective in diminishing serum glucose levels in fasting rats [12] due to phycocyanin, which is capable of reducing concentrations of circulating glucose [13]. According to studies by Layam and Reddy [18], when this alga is administered at a concentration of $15 \mathrm{mg} / \mathrm{kg}$ body weight, it can raise serum insulin levels in DM-1 rats.

Given the difficulties encountered in studies that involve hepatic steatosis in human subjects, several studies have been performed using animal subjects, which permits researchers strict control of nutrition and environment and also the analysis of specific tissues, such as hepatic and myocardial tissues. Thus, the objective of the present study was to verify the effects spirulina intake and of swimming training on the lipid profile, in hepatic steatosis and on the accumulation of lipids in myocardial and skeletal muscle of diabetic Wistar rats.

\section{Materials and methods}

\section{Animals and Treatment}

The study used young Wistar rats (60 days old), which came from the Central Vivarium (Biotério Central) of UNESPA - at the Botucatu Campus and were maintained in the vivarium of the biodynamic laboratory of the Department of Physical Education, Biosciences Institute of UNESP - Rio Claro Campus. The animals were housed in polyethylene cages (five animals per cage) and kept at a controlled room temperature of 23 $\pm 1^{\circ} \mathrm{C}$, with a photoperiod of 12 hours of light/12 hours of dark with food and water ad libitum. The experiment was conducted in accordance with current Brazilian legislation and standards of the Brazilian College of Animal Experimentation (Colégio Brasileiro de Experimentação Animal-COBEA). All standards were adhered to rigorously. The use of animals in this study was approved by the ethics committee at the Biosciences Institute at UNESP - Rio Claro (protocol 5111 of 08/20/09).

\section{Induction of Diabetes}

Experimental diabetes was induced by administration of alloxan monohydrate (Sigma, $32 \mathrm{mg} \cdot \mathrm{kg}^{-1}$ of body weight) dissolved in citrate $0.01 \mathrm{M}, \mathrm{pH} 4.5$, injected into the penile vein. After this procedure, the animals were returned to their cages and received, in the first 24 hours post-alloxan, a solution of water and glucose (15\%), in addition to feed [19]. Two weeks after administration of the drug, the blood glucose level of the animals was tested for evidence of a diabetic state. The animals that had a blood glucose level equal to or greater than $190 \mathrm{mg} \cdot \mathrm{dL}^{-1}$ were included in the study.

\section{Experiment Design}

After the induction of type 1 diabetes, the animals were randomly distributed into four groups (10 per group): Diabetic Control (DC) - composed of alloxan diabetic rats that were given a control diet and no exercise; Diabetic Spirulina (DS) - composed of alloxan diabetic rats fed with a diet that included spirulina and no exercise; Diabetic Spirulina and Exercise (DSE) - composed of alloxan diabetic rats fed with a diet that included spirulina and that exercised; Diabetic Exercise (DE) - composed of alloxan diabetic rats fed with a control diet and that exercised.

\section{Diets}

Following the recommendations of the American Institute of Nutrition AIN-M93 [20], isocaloric and semipurified diets were utilised; the control diet for the animals in the control (DC) and exercise (DE) groups contained $17 \%$ casein protein, and the rats in the spirulina groups (DS and DSE) were fed with a diet containing $17 \%$ spirulina protein. The control diet was composed of the following $(\%)$ : corn starch $=39.7$, dextrin $=13.2$, sucrose $=10$, soy oil $=7$, microcellulose $=5$, a mixture of six minerals $=3.5$, and a mixture of vitamins $=1$. A detailed description of the mineral and vitamin mixtures can be found in Reeves et al. [20]. The spirulina diet contained the same quantities of carbohydrates and lipids as the control diet. There were adjustments made only in the contents of the six minerals, the vitamins, and the fibres, taking into account the levels of these elements already in the spirulina, so that the recommendations of AIN-M93 for these nutrients would be maintained [21].

\section{Adaptation to the liquid medium and exercise protocol}

In the first week, the animals were put into contact with shallow water for adaptation to the liquid medium. From the second week, they had swimming exercise with increasing amounts of time. The training sessions were held in collective tanks with a constant water temperature of $31 \pm 1^{\circ} \mathrm{C}$, for 1 hour/day, 5 days/week, for a 
total period of 44 days. During the exercise, a backpack was attached to the thorax of the animal with a load equivalent to $3.5 \%$ of body weight. This protocol was selected to represent aerobic exercise below the lactate threshold for diabetic rats [22].

\section{Assessments of animals prior to their sacrifice}

During the entire experimental period, all the animals had their body mass, water and food intake registered. The results were analysed calculating the area under the curves in the variations of body mass and food intake over time using the trapezoidal rule [23].

\section{Assessments of animals after their sacrifice}

At the end of the experimental period, 48 hours after the final "in vivo" evaluations, at feed and rest conditions, all the rats were anaesthetised in a $\mathrm{CO}_{2}$ chamber until they were sedated. They were then exsanguinated, and their blood was collected. The blood was centrifuged at $3000 \mathrm{rpm}$ for 15 minutes, and analyses of glucose, total cholesterol, triglycerides, HDL cholesterol, LDL cholesterol, total protein, and albumin were performed using samples of supernatant serum, through colourimetric methods with commercial colourimetry test kits (Laborlab ${ }^{\circledR}$, Guarulhos - SP/Brazil). Free fatty acid (FFA) were also analysed according to the Regow method [24], and insulin was measured by radioimmunoassay [25].

Samples of the left ventricle, the liver, and the gastrocnemius muscle were taken to determine the concentrations of triglycerides and total lipids. The samples were placed into tubes containing $0.1 \%$ Triton X-100. They were then homogenised with a Polytron ${ }^{\circledR}$ for 20 seconds at a maximum velocity. After this procedure, the samples were centrifuged at $4.000 \mathrm{rpm}$ for 10 minutes. The supernatant was extracted to determine the triglycerides and total lipid using spectrophotometry with a commercial kit (Laborlab ${ }^{\circledR}$, Guarulhos - SP/Brazil).

\section{Statistical Analysis}

The results are expressed as means and standard deviations. After checking the data for normalcy using the Shapiro-Wilk test, the values of the lipid profile, plasma proteins, adipose tissue proteins, areas under the curve of variations in body mass and the intake of food and water during the experiment were compared between the groups using analysis of variance - one way ANOVA with Tukey's post-hoc test. The adopted significance level was $\mathrm{p}<0.05$.

\section{Results}

The results of body mass in each group are shown in Figure 1. All groups had significantly reduced body mass by the end of the 44 days of training in relation to pre-intervention values as indicated by the area under the curve of body mass over time (Figure 1-a). Furthermore, the statistical analysis did not show a significant difference between the groups regarding the change $(\Delta)$ in body mass (final value of body mass - initial value of body mass) during the experiment, as shown in Figure 1 -b. There was also no difference between the groups when the values of the area under the curve of body mass were compared, as demonstrated in Figure 1-c.

The results of water intake in each group are illustrated in Figure 2-a. There was no statistical difference between the areas under the curve of water intake over time (Figure 2-b) when comparing all groups. The statistical analysis also did not show a significant difference between areas under the curve of food intake when comparing all groups (Figures 2-c and 2-d).

The results of serum concentrations of glucose, insulin, total, HDL and LDL cholesterol, triglycerides, FFA, total proteins, and plasma albumin of all groups are presented in Table 1. For the concentrations of serum insulin, the DS group had a significantly lower value when compared to the DC, DE, and DSE groups. The statistical analysis did not show differences in concentrations of glucose, total cholesterol, triglycerides, FFA, or total proteins in the groups studied.

The concentrations of LDL cholesterol were 34 and $42 \%$ less in the DS and DSE groups, respectively, in relation to the DC group. The HDL cholesterol levels were $20 \%$ lower in the DSE group in relation to the DC group. Furthermore, the concentration of albumin was $17 \%$ lower in the DSE group in relation to the DC group.

The results of the tissue concentrations of lipids are presented for all groups in Table 2. The statistical analysis did not show a significant difference in triglyceride concentrations in muscular tissue or in the left ventricle myocardial groups but did show that the concentration of hepatic triglycerides was $43 \%$ less in the DS group in relation to the DC group. In turn, the concentrations of total hepatic lipids were 46,44 and $43 \%$ lower in relation to the DC group for the DS, DSE and DE groups, respectively.

\section{Discussion}

This study aimed at assessing the effects of spirulina intake and physical exercise on circulating and tissue lipid levels (hepatic, myocardial, and skeletal muscle) in diabetic Wistar rats. The principal finding of our study was that spirulina in the diet of these rats resulted in an attenuation of fatty deposits in the liver as well as lower plasma levels of LDL cholesterol in comparison to the diabetic control group that did not receive treatment.

In fact, the literature has shown conflicting results in studies including a diet with spirulina and exercise. One 


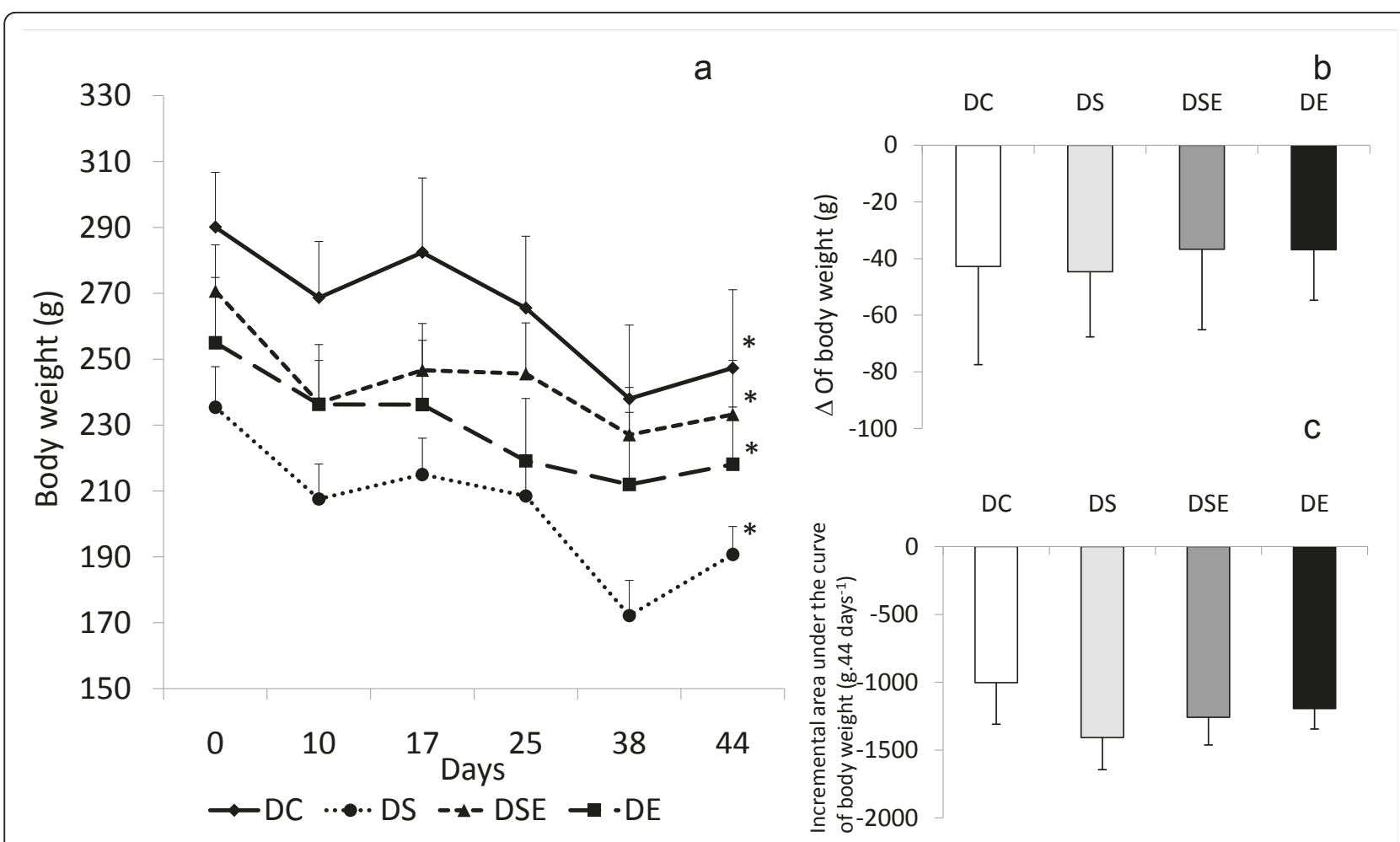

Figure 1 Mean and standard error of body mass - a; the difference between body mass pre- and post-intervention ( $\triangle=$ variation of mass in relation to initial mass over time) - b; area under the curve of body mass over time of the body mass - c. DC - control group; DS - group with spirulina intake and without exercise; DSE - group with spirulina intake and with exercise; and DE - group without intake of spirulina and with exercise (10 animals/group).

of the first studies with rats consuming spirulina showed a reduction in total cholesterol levels when examining the lipid profile [26]. Since then, various studies have been conducted using animal $[17,27,28]$ and human models $[29,30]$.

In relation to the intake of water and food, the statistical analysis showed that there was no significant difference between groups (Figure 2). Furthermore, total protein concentrations and serum albumin that can be used as measures of the nutritional and hydration states of animals showed values quite similar to those already reported by other authors that also study active and sedentary diabetic Wistar rats [31].

Using an experimental model, Kato et al. [27] submitted rats to a diet rich in cholesterol with and without spirulina supplementation. In this study, the authors observed an increase in total cholesterol levels overall, LDL + VLDL cholesterol and phospholipids in the serum of the group that did not ingest spirulina. However, there was a significant reduction in the levels of these cholesterol fractions when the animals were supplemented with $16 \%$ spirulina.

Iwata et al. [17] observed that spirulina supplementation inhibited the increase of HDL - cholesterol, triglycerides, and phospholipids in the plasma. On the other hand, there was no statistical significance observed between the control group and the groups supplemented with spirulina when lipid levels in the liver were compared. Furthermore, the authors reported an increase in lipoprotein lipase enzyme activity in the animals that received spirulina supplementation.

The results found in the literature on the relationship between lipid profiles and spirulina intake need more controlled studies. Recently Cheong et al. [32] affirmed that the anti-hypercholesterolaemia mechanisms of spirulina are still not well understood, although some authors suggest that the addition of this alga into the diet diminishes the intestinal absorption of cholesterol as well as the re-absorption of bile acids in the ileum. Thus, they suggest that spirulina can be considered a functional food capable of reducing the levels of cholesterol and consequently preventing atherosclerosis.

Our results seem to corroborate the finding of Kato et al. [27], who show a reduction in the levels of serum cholesterol in animals supplemented with spirulina. However, the unexpected finding in our data was the reduction of HDL cholesterol found in the DSE group in relation to the DC group. The literature still contains 


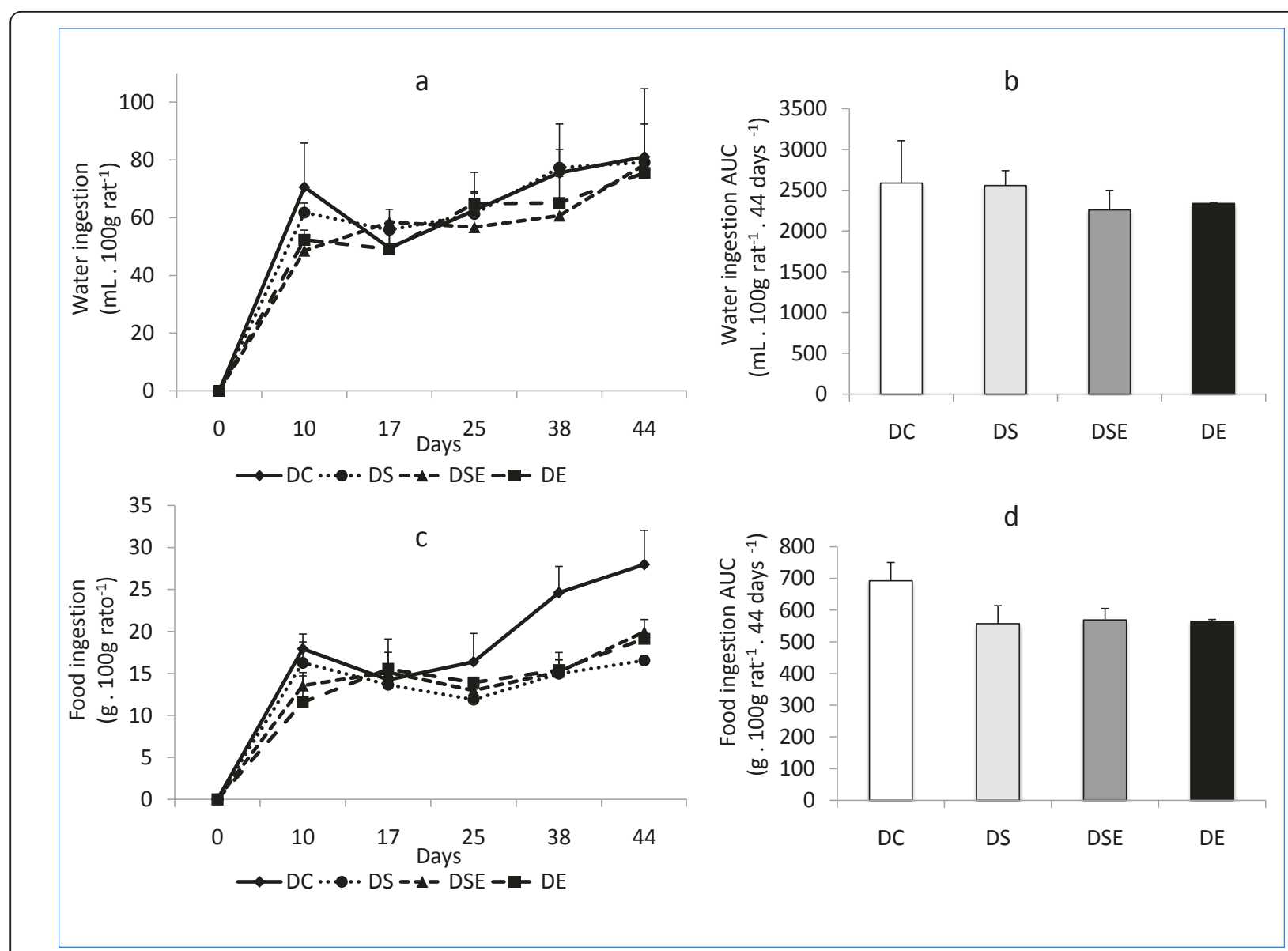

Figure 2 Mean and standard error of water consumption (a) and area under the curve (b) of all groups. Median values of food consumption (c) and the area under the curve (d) of all groups. DC - control group; DS - group with spirulina intake and without exercise; DSE group with spirulina intake and with exercise; and DE - group without intake of spirulina and with exercise (10 animals/group).

conflicting findings in relation to this fraction of cholesterol and spirulina supplementation. Iwata et al. [17] suggest that spirulina can inhibit or augment HDL cholesterol, and it seems that this variable does not have a determined variable according to the modifications caused by the action of spirulina.
Corroborating the work of Blé-Castillo et al. [33], who observed that the administration of spirulina prevented an increase of total hepatic lipids (40\%), our study found a positive effect from both exercise and a diet including spirulina when we verified the reduction in total lipids in hepatic tissue (in the DS, DSE and DE groups in

Table 1 Serum analysis at the end of the experiment.

\begin{tabular}{|c|c|c|c|c|}
\hline & $\mathrm{DC}$ & DS & DSE & $\mathrm{DE}$ \\
\hline Total Cholesterol $\left(\mathrm{mg} \cdot \mathrm{dL}^{-1}\right)$ & $108.8(9.8)$ & $105.5(4.9)$ & $94.3(6.2)$ & $91.2(4.0)$ \\
\hline $\mathrm{HDL}$ - Cholesterol $\left(\mathrm{mg} \cdot \mathrm{dL}^{-1}\right)$ & $19.8(0.8)$ & $17.7(0.7)$ & $15.7(1.0)^{*}$ & $18.4(0.7)$ \\
\hline LDL - Cholesterol (mg.dL $\left.{ }^{-1}\right)$ & $64.0(7.3)$ & $42.2(5.7)^{*}$ & $37.4(3.9)^{*}$ & $52.2(3.8)$ \\
\hline Triglycerides $\left(\mathrm{mg} \cdot \mathrm{dL}^{-1}\right)$ & $105.6(9.9)$ & $237.2(39.9)$ & $237.8(46.4)$ & $112.7(22.2)$ \\
\hline Free Fatty Acids $\left(\mathrm{mg} \cdot \mathrm{dL}^{-1}\right)$ & $0.66(0.05)$ & $0.66(0.06)$ & $0.62(0.04)$ & $0.67(0.04)$ \\
\hline Albumin (mg\%) & $2.61(0.06)$ & $2.42(0.02)$ & $2.28(0.14)^{*}$ & $2.56(0.06)$ \\
\hline Total Proteins (mg\%) & $7.66(0.36)$ & $7.19(0.11)$ & $7.34(0.32)$ & $7.47(0.19)$ \\
\hline Glucose $\left(m g \cdot d L^{-1}\right)$ & $303.20(70.69)$ & $289.25(106.65)$ & $248.88(84.92)$ & $275.40(90.90)$ \\
\hline Insulin $\left(U \cdot \mathrm{mL}^{-1}\right)$ & $1.64(0.21)$ & $0.43(0.21)^{*}$ & $12.69(3.24)$ & $9.73 \pm 3.68$ \\
\hline
\end{tabular}

Results expressed with means and (standard errors) of 10 animals/group. DC: Diabetic Control, DS: Diabetic Spirulina, DSE: Diabetic Spirulina Exercise and DE: Diabetic Exercise. Statistical Difference (ANOVA $p<0.05$ ), ${ }^{*}=$ different from DC. 
Table 2 Tissue lipids analyses at the end of the experiment.

\begin{tabular}{lcccc}
\hline & DC & DS & DSE & DE \\
\hline $\begin{array}{l}\text { Liver } \\
\quad \text { Total Lipids (mg }\end{array}$ & 07.61 & 04.15 & 04.24 & 04.36 \\
$\quad$ \%) & $(1.52)$ & $(0.17)^{*}$ & $(0.29)^{*}$ & $(0.49)^{*}$ \\
$\quad \begin{array}{l}\text { Triglycerides (mg } \\
\text { \%) }\end{array}$ & 18.52 & 10.59 & 11.11 & 12.12 \\
$\begin{array}{l}\text { Gastrocnemius } \\
\text { Muscle }\end{array}$ & $(3.87)$ & $(1.05)^{*}$ & $(1.32)$ & $(1.94)$ \\
$\quad$ & & & \\
$\quad \begin{array}{l}\text { Triglycerides (mg } \\
\quad \text { ) }\end{array}$ & 12.04 & 08.82 & 08.38 & 09.17 \\
$\begin{array}{l}\text { Left Ventricle } \\
\quad \text { Triglycerides (mg } \\
\quad \text { \%) }\end{array}$ & $5.95(0.59)$ & $(0.95)$ & $(0.84)$ & $(0.98)$ \\
\hline
\end{tabular}

Results expressed with means and (standard errors) of 10 animals/group. DC Diabetic Control, DS: Diabetic Spirulina, DSE: Diabetic Spirulina Exercise and DE: Diabetic Exercise. Statistical Difference (ANOVA $p<0.05$ ), ${ }^{*}=$ different from DC.

comparison to the DC group) and the triglycerides of these same tissues (the DS group in comparison to the DC group).

According to the results found in the circulating lipid profile, it is possible to observe that the association between the effects of diet with spirulina and exercise seem to cause major changes. When analysed from this perspective, the HDL and LDL cholesterols were different for the DSE group in relation to the DC group. However, when we look at the specific effect of one of the conditions, the results point to the possibility that only spirulina causes modifications, causing a statistical difference in the LDL cholesterol. We understand that the positive effects found for hepatic and plasma levels are very important when we analyse lipid metabolism, and that spirulina, mainly when associated with exercise, seems to be an agent capable of causing interesting modifications in this metabolism.

By analysing the study of Moura et al. [34], we verified that the rats from the same breed used here (Wistar), non-diabetic and maintained with a balanced diet showed concentrations of total hepatic tissue lipids of $3.5 \pm 0.4 \mathrm{mg} \%$ for sedentary animals and of $3.5 \pm 0.5$ $\mathrm{mg} \%$ for water-exercised animals. Compared with these data, we report results that were approximately 117,24 , 21 and 18\% higher in the DC, DS, DSE and DE groups, respectively. Thus, we can assert that hepatic steatosis was induced in the DC group and present evidence that the intervention of spirulina and/or exercise seems to reduce the accumulation of total hepatic lipids in diabetic rats, thereby attenuating hepatic steatosis.

\section{Conclusion}

Based on our results, we conclude that spirulina intake can provide lower levels of circulating LDL cholesterol in comparison to aerobic training in diabetic Wistar rats. Furthermore, both spirulina intake and physical exercise cause an improvement in hepatic steatosis in these animals.

\section{Conflicts of interest}

The authors declare that they have no competing interests.

\section{List of abbreviations}

DM-1: type 1 diabetes mellitus; DM-2: type 2 diabetes mellitus; NAFLD: nonalcoholic fatty liver disease; FFA: free fat acids.

\section{Acknowledgements}

The authors would like to thank the technicians at the Biodynamic Laboratory of the Physical Education Department at UNESP Campus Rio Claro for their indispensible support, Clarice Sibuya and José Roberto Rodrigues, and the National Council of Scientific and Technological Development - CNPq, the Foundation for Research Support of São Paulo FAPESP for the financial support and FUNDUNESP. We also thank Corn Products Brasil ${ }^{\mathbb{R}}$ for the donation of the dietary materials used in this experiment.

\section{Authors' contributions}

All authors was responsible for the experimental design, data collection, statistical analysis and preparation of the manuscript. All authors worked read and approved the final manuscript.

Received: 14 March 2011 Accepted: 15 May 2011

Published: 15 May 2011

\section{References}

1. Kelly MA, Rayner ML, Mijovic CH, Barnett $\mathrm{AH}$ : Molecular aspects of type 1 diabetes. Mol Pathol 2003, 56:1-10.

2. Colca JR, Dailey CF, Palazuk BJ, Hillimen RM, Dinh DM, Melchior GW, Spilman $\mathrm{CH}$ : Pioglitazone hydrochloride inhibits cholesterol absorption and lowers plasma cholesterol concentrations in cholesterol-fed rats. Diabetes 1991, 40:1669-1674.

3. Carew TE, Koschinsky T, Mayers SB, Steinberg D: A mechanism by which high-density lipoproteins may slow the atherogenic process. Lancet 1976, 1:1315-1317

4. Diehl AM: Nonalcoholic steatohepatitis. Semin Liver Dis 1999, 19:221-229.

5. Castaneda C: Type 2 diabetes mellitus and exercise. NCC 2001, 3:349-58.

6. Schneider SH, Ruderman NB: Exercise and NIDDM (technical review). Diabetes Care 1990, 13:785-789.

7. De Caire GZ, De Cano MS, De Mule CZ, Steyerthal N, Piantanida M: Effect of Spirulina platensis on glucose, uric acid and cholesterol levels in the blood of rodents. Int J Exp Bot 1995, 57:93-6.

8. Hirata T, Tanaka M, Ooike M, Tsunomura T, Sakaguchi M: Antioxidant activities of phycocyanobilin prepared from Spirulina platensis. J Appl Phycol 2000, 12:435-439.

9. Hosoyamada Y, Takai T, Kato T: Effects of water-soluble and insoluble fractions of Spirulina on serum lipid components and glucose tolerance in rats. J Jpn Soc Nutri Food Sci 1991, 44:273-277.

10. Belay A, Ota Y, Miyakawa K, Shimatsu H: Current knowledge on potential health benefits of spiruline. J Appl Phys 1993, 5:235-241.

11. Nakaya N, Honma Y, Goto Y: Cholesterol lowering effect of Spirulina. Nutr Rep Int 1988, 37:1329-1337.

12. Kay RA: Microalgae as food and supplement. Crit Rev Food Sci Nutr 1991, 30:555-573.

13. Ambrosi MA, Reinehr CO, Bertolin TE, Costa JAV, Colla LM: Propriedades de saúde de Spirulina spp. Rev Ciênc Farm Básica Apl 2008, 29:109-117.

14. Fica V, Olteanu D, Oprescu S: Use of spiruline as an adjuvant nutrient factor in the therapy of the diseases accompanying a nutritional deficiency. Rev Med Interna Neurol Psihiatr Neurochir Dermatovenerol Med Internam 1984, 36:225-232.

15. Becker EW, Jakober R, Luft D, Schmülling RM: Clinical and biochemical evaluation of the alga Spirulina with regard to its application in the 
treatment of obesity. A double-blind cross-over study. Nutr Rep Int 1986, 33:565-572.

16. Hernández AR, Castillo JLB, Oropeza MAJ, Zagoya JCD: Spirulina maxima prevents fatty liver formation in CD-1 male and female mice with experimental diabetes. Life Sci 2001, 69:1029-1037.

17. Iwata K, Inayama T, Kato T: Effects of Spirulina platensis on plasma lipoprotein lipase activity in fructose-induced hyperlipidemic rats. J Nutr Sci Vitaminol 1990, 36:165-71.

18. Layam A, Reddy CLK: Antidiabetic property of spirulina. Diabetol Croat 2007, 35:27-48

19. Luciano E, Lima FB: Metabolismo de ratos diabéticos treinados submetidos ao jejum e ao exercício agudo. Rev Ciênc Bioméd 1997, 18:47-60.

20. Reeves PG, Nielsen FH, Fahey GC: AIN-93 purified diets for laboratory rodents: final report of the American Institute of Nutrition AdHoe Writing Committee on the Reformulation of AIN-76A. J Nutr 1993, 123:1938-1951

21. Voltarelli FA, Mello MAR: Spirulina enhanced the skeletal muscle protein in growing rats. Eur J Nutr 2008, 47:393-400.

22. Oliveira CAM, Luciano E, Marcondes MCCG, Mello MAR: Effects of swimming training at the intensity equivalent to aerobic/anaerobic metabolic transition in alloxan diabetic rats. J Diabetes Complicat 2007, 21:258-264.

23. Mathews JNS, Altman DG, Campbell MJ, Royston P: Analysis of serial measurements in medical research. BMJ 1990, 27:230-235

24. Regow BJM, Cornelissen PJ, Helder RA, Spijkers JB, Weeber YM: Specific determination of free fatty acid in plasm. Clin Acta Chim 1971, 31:187-195.

25. Herbert V, Lau KS, Gottlieb CW, Bleicher SJ: Coated Charcoals immunoassay of insulin. J Clin Endocrinol Metab 1965, 25:1375-84.

26. Devi MA, Venkataraman LV: Hypocholesterolemic effect of blue green algae Spirulina platensis in albino rats. Nutr Rep Int 1983, 28:519-530.

27. Kato T, Takemoto K, Katayama H, Kuwabara Y: Effects of Spirulina (Spirulina platensis) on dietary hypercholesterolemia in rats. J Jap Soc Nutr Food Sci 1984, 37:323-332.

28. Meineri $G$, Ingravalle F, Radice $E$, Aragno M, Peiretti PG: Effects of high fat diets and spirulina platensis supplementation in new Zealand White Rabbits. J Anim Vet Adv 2009, 8:2735-2744.

29. Parikh $\mathrm{P}$, Mani $U$, lyer $\mathrm{U}$ : Role of spirulina in the control of glycemia and lipidemia in type 2 diabetes mellitus. Digestive Diseases and Sciences 2001, 4:193-199.

30. Torres-Duran PV, Ferreira-Hermosillo A, Juarez-Oropeza MA: Antihyperlipemic and antihypertensive effects of Spirulina maxima in an open sample of mexican population: a preliminary report. Lipids Health Dis 2007, 6:33.

31. Luciano E, Mello MAR: Efeitos do exercício físico crônicos sobre as proteínas no diafragma de ratos diabéticos. Motriz 1999, 5:146-51.

32. Cheong SH, Kim MY, Sok DE, Hwang SY, Kim JH, Kim HR, Lee JH, Kim YB, Kim MR: Spirulina Prevents Atherosclerosis by Reducing Hypercholesterolemia in Rabbits Fed a High-Cholesterol Diet. J Nutr Sci Vitaminol 2010, 56:34-40

33. Blé-Castillo JL, Rodríguez-Hernández A, Miranda-Zamora R, JuárezOropeza MA, Díaz-Zagoya JC: Arthrospira maxima prevents the acute fatty liver induced by the administration of simvastatin, ethanol and a hypercholesterolemic diet to mice. Life Sci 2002, 70:2665-2673.

34. Moura LP, Araújo MB, Gomes RJ, Leme JACA, Luciano E, Moura RF, Ribeiro C, Voltarelli FA: Aerobic Conditioning and Hepatic Steatosis Markers in Exercise-Trained Diabetic Rats. Med sci sports exerc 2009, 41: S509-S509.

doi:10.1186/1476-511X-10-77

Cite this article as: Moura et al.: Exercise and spirulina control non-

alcoholic hepatic steatosis and lipid profile in diabetic Wistar rats. Lipids in Health and Disease 2011 10:77.

\section{Submit your next manuscript to BioMed Central and take full advantage of:}

- Convenient online submission

- Thorough peer review

- No space constraints or color figure charges

- Immediate publication on acceptance

- Inclusion in PubMed, CAS, Scopus and Google Scholar

- Research which is freely available for redistribution

Submit your manuscript at www.biomedcentral.com/submit 